\title{
Factorial Invariance of Self-Efficacy in the Sociocultural Sphere Scale on Men and Women University Students
}

\author{
Veronica Benavides Pando, (Dr.) \\ Julio Cesar Guedea Delgado, (Dr.) \\ Edgar Francisco Ordonez Bencomo, (MC.) \\ Javier Bernabe Gonzalez Bustos, (M.A.P.E.) \\ Juan Cristobal Barron Lujan, (M.C.) \\ Autonomous University of Chihuahua, Mexico
}

doi: 10.19044/ejes.v4no1a53ＵRL:http://dx.doi.org/10.19044/ejes.v4no1a53

\begin{abstract}
The present study analyses the psychometric properties of the Selfefficacy in the Sociocultural Sphere Scale in men and women university students. The overall sample consisted of 1545 subjects: 616 women and 929 men, with a mean age of 18.11 years $(S D=0.69)$ and 18.27 years $(S D=0.75)$ respectively. Psychometric analysis showed that two-factorial structure (promotion of the culture and cultural identity) was viable and adequate for both populations (men and woman) according to the established psychometric requirements when the informers are the students themselves. The results showed that factor structure, factor loadings and intercepts of the instrument could be considered invariant across groups; however, there are differences between groups for the means of factors promotion of the culture and cultural identity.
\end{abstract}

Keywords: Self-efficacy, factor structure, measurement invariance, multi group confirmatory factor analysis.

\section{Introduction}

The beliefs that people have about themselves are crucial for the control and personal competence when dealing with problems, challenges and decisions that have to be confronted during a lifetime. Among the beliefs of self-reference used by individuals to interact with their environment are self-efficacy beliefs (Pajares, 2001).

The application of the theory of self-efficacy of Bandura in education shows how students with high self-efficacy expectations have greater 
academic motivation (Brown, Tramayne, Hoxha, Telander, \& Lent, 2008; Caprara et al., 2008). Also, they perform better, they are more able to effectively self-regulate their learning and show greater intrinsic motivation when they learn (Cartagena, 2008; Salanova, Llorens, \& Shaufeli, 2011). Consequently, improving self-efficacy expectations increases the motivation and performance in learning tasks (Adeyemo, 2007). Therefore, is not enough to be able to do something, people must be judged themselves capable or able to use the abilities and personal skills to a variety of circumstances, including emotional reactions to difficult situations (Blanco, Martínez, Zueck, \& Gastélum, 2011).

Therefore, the greater perceived efficacy, the greater degree of effort that is invested and the greater persistence in achieving the proposed goal; situation of utmost importance for a person who is in a learning process to be successful (Ornelas et al, 2012; Schmidt, Messoulam, \& Molina, 2008).

Definitely, self-efficacy beliefs represent a cognitive mechanism that mediates between knowledge and action and determines, along with other variables, the success of own actions (Sansinenea et al., 2008).

This instrumental study (Montero \& León, 2005) aims to provide empirical support for the factorial division of Self-efficacy in the Sociocultural Sphere Scale; which it is justified by the importance of checking the factorial structure and the psychometric equivalence of the instrument in different groups; since in the context of intergroup comparison, it is essential to consider the need to carry out the adaptation of an instrument of psychological measure that fulfills all the criteria of equivalence, but above all consider whether the same factor structure is applicable to different groups of subjects or, more generically, to different populations (Abalo, Lévy, Rial, \& Varela, 2006; Arbuckle, 2012).

This paper aims, firstly, to investigate whether the psychometric results proposed by Blanco et al (2011) for the Self-efficacy in the Sociocultural Sphere Scale (EAAAS) replicate, and secondly, expand them. To do this, first the degree of congruence of the factorial structure of EAAAS obtained in this study will be checked and the one reported by (Blanco et al., 2011). Secondly, the factorial invariance between samples of this study is calculated.

\section{Methods:}

Participants

The sample of 1545 participants, 616 (39.1\%) woman and 929 (60.1\%) men, was obtained by a convenience sample, trying to cover the representation of the different degrees offered at the Autonomous University of Chihuahua. Women ages was ranging between 17 and 20 years, with a mean of 18.11 and a standard deviation of 0.69 years; and men ages was 
ranging between 17 and 20 years, with a mean of 18.27 and a standard deviation of 0.75 years.

\section{Instrument}

Self-efficacy in the Sociocultural Sphere Scale (EAAAS) is a Likert questionnaire assisted by computer of 9 items (Muñoz et al., 2012) where the respondent answers on a scale of 0 to 10, how capable he feels in every one of the items of the factors Promotion of the culture and Cultural Identity.

\section{Procedure}

Were invited to participate in the study the first year students of the degrees offered at the Autonomous University of Chihuahua; those who agreed to participate signed the corresponding consent letter. Then, the instrument explained above was applied using a personal computer using the administrator of the instrument module (Muñoz et al., 2012), in a session of about 20 minutes; in the computer labs of the participating academic units. At the beginning of each session students were given a brief introduction on the importance of the research and how to access the instrument; instructions on how to respond were in the first screens; before the first instrument item. At the end of the session students were thanked for their participation.

Once the instrument was applied, data was collected by the results generator module of scales editor, version 2.0 (Blanco et al., 2013).

\section{Data Analysis}

The psychometrical analysis was applied in two stages: 1) Factorial Confirmatory Analysis and 2) Invariance Factorial Analysis; so that it could obtain evidence that presents the best properties for the scores confirmation of self-efficacy in academic behaviors on men and women university students.

To conduct the confirmatory factorial analysis for each sample, AMOS 21 software was used (Arbuckle, 2012), variances in terms of error were specified as free parameters, in every latent variable (factor) a structural coefficient was set associated to one, so that the scale was equal to the superficial variables (items). The estimated method used was the maximum likelihood; following the recommendation of Thompson (2004), so when the confirmatory factorial analysis is used, it is necessary to verify not only the adjustment of the theoretical model but it is recommended to compare the fit indexes of some alternative models to select the best.

To evaluate the adjustment model statistical chi-squared, the Goodness-of-fit index (GFI), and the root mean square error of approximation (RMSEA) were used as absolute adjustment measures. Adjusted goodness of fit index (AGFI) the Tucker-Lewis Index (TLI), the 
comparative fit index (CFI) were used as incremental fit indices. Parsimony normed fit index (PNFI), the Parsimony Goodness-of-fit index (PGFI), the chi-squared fit index divided by degrees of freedom (CMIN/GL) and the Akaike Information Criterion (AIC) were used as parsimony fit indices (Gelabert et al., 2011).

Finally, an analysis of the factorial invariance of the models of measurement obtained was made, following the recommendations of Abalo et al. (2006), and was calculated the reliability of each of the dimensions through Cronbach's alpha and Omega coefficient (Revelle \& Zinbarg, 2009).

\section{Results:}

\section{Confirmatory Factorial Analysis}

According to the results obtained in Table1 in the Confirmatory Factorial Analysis of 9 items grouped in two factors in the sample of women is optimal (GFI .992 y RMSEA .009) and according to the incremental adjustment measures and Parsimony significantly superior to the independent model and very similar to the saturated model.

Furthermore, the confirmatory factor analysis on the sample of men (Table 1) shows again that the measuring model of two factors is optimal (GFI .986 y RMSEA .042) and according to the incremental adjustment measures and Parsimony significantly superior to the independent model and very similar to the saturated model.

Table 1. Absolute, incremental and Parsimony fit indexes for the generated models. Confirmatory factor analysis for women and men.

\begin{tabular}{|c|c|c|c|c|c|c|c|c|}
\hline \multirow[b]{2}{*}{ Model } & \multicolumn{3}{|c|}{ Absolute indexes } & \multicolumn{3}{|c|}{ Incremental indexes } & \multicolumn{2}{|c|}{ Parsimony indexes } \\
\hline & $\chi^{2}$ & GFI & RMSEA & AGFI & TLI & CFI & CMIN/DF & AIC \\
\hline \multicolumn{9}{|c|}{ Factor solution for women } \\
\hline Independent & $2440.597 *$ & .372 & .330 & .214 & .000 & .000 & 67.794 & 2458.597 \\
\hline Saturated & 0.000 & 1.000 & & & & 1.000 & & 90.000 \\
\hline 2 factors & 23.022 & .992 & .009 & .984 & .999 & 1.000 & 1.046 & 69.022 \\
\hline \multicolumn{9}{|c|}{ Factor solution for men } \\
\hline Independent & 3816.989* & .363 & .336 & .203 & .000 & .000 & 106.027 & 3834.989 \\
\hline Saturated & 0.000 & 1.000 & & & & 1.000 & & 90.000 \\
\hline 2 factors & $57.354 *$ & .986 & .042 & .972 & .985 & .991 & 2.607 & 103.354 \\
\hline
\end{tabular}

Note: $* \mathrm{p}<.05$; GFI = goodness of fit index; RMSEA = root mean square error of approximation; AGFI = adjusted goodness of fit index; TLI = Tucker-Lewis index; CFI = comparative fit index; CMIN/DF = chi-squared fit index divided by degrees of freedom; AIC = Akaike information criterion

According to the results of Table 2, in both samples, except item 4, all of the items properly saturate in their dimension (factor) provided. Observing moderate high intercorrelations among the factors showing a not very good discriminant validity. 
Invariance of the factorial structure among men and women university students

The fit indexes obtained (Table 3) allow to accept the equivalence of the basic measuring models between the two subsamples. Although the value of Chi-squared exceeds to that required to accept the hypothesis of invariance, the rest of the indexes contradict this conclusion (GFI .988; CFI .994; RMSEA .023; AIC 172.370) this allows us to accept the base model of invariance (model without restrictions).

Table 2 Standardized solutions for the confirmatory factor analysis in both samples.

Factor weights

\begin{tabular}{|c|c|c|c|c|c|}
\hline \multirow{2}{*}{ Item } & & \multicolumn{2}{|l|}{ Factor 1} & \multicolumn{2}{|l|}{ Factor 2} \\
\hline & & Women & Men & Women & Men \\
\hline 7 & $\begin{array}{l}\text { Participate in proposals that contribute to the } \\
\text { development of social and cultural improvement. }\end{array}$ & .82 & .82 & & \\
\hline 9 & Act as a promoter of life quality. & .82 & .82 & & \\
\hline 8 & $\begin{array}{l}\text { Interact with different social groups promoting } \\
\text { quality of life. }\end{array}$ & .79 & .82 & & \\
\hline 6 & $\begin{array}{l}\text { Generate an interaction with the environment, } \\
\text { encouraging the community cultural level. }\end{array}$ & .76 & .76 & & \\
\hline 1 & $\begin{array}{l}\text { Actively participate in processes of creation, } \\
\text { conservation and diffusion of the culture. }\end{array}$ & .73 & .72 & & \\
\hline 5 & $\begin{array}{l}\text { Analyze the phenomena of globalization and } \\
\text { sustainable development from different } \\
\text { perspectives. }\end{array}$ & .65 & .63 & & \\
\hline 3 & $\begin{array}{l}\text { Show values towards the different traditions and } \\
\text { multicultural difference. }\end{array}$ & & & .83 & .75 \\
\hline 2 & Act with respect and tolerance & & & .55 & .65 \\
\hline 4 & Identify with the culture of my state and country. & .23 & .27 & .32 & .30 \\
\hline \multicolumn{6}{|c|}{ Correlations between factors } \\
\hline & tor 1 & - & - & & \\
\hline & tor 2 & .61 & .65 & - & - \\
\hline
\end{tabular}

Note: $\mathrm{F} 1=$ promotion of the culture; F2 = Cultural Identity

Adding to the base model restrictions on factorial weights the metric invariance was characterized. The values obtained from table 3 permit to accept this invariance level. The goodness of fit index (GFI .986) and the root mean square error of approximation (RMSEA .024) continue to provide convergent information in this direction. Also, the Akaike Information Criterion (AIC 175.349) and Bentler comparative fit index (CFI .992) do not suffer large variations over the previous model. Using the criteria for the evaluation of the nested models proposed by Cheung and Rensvold (2002), who suggest that if the calculation of the difference of the CFI of both nested models diminish in .01 or less, the restricted model is taken for granted therefore the compliance of the factorial invariance. The difference of the CFIs obtained (.002) allows to accept the metrical invariance model. 
We can conclude up to this point that factorial charges are equivalent in the two samples.

Having demonstrated the metric invariance between the samples, we evaluate the equivalence between intercepts (strong factorial invariance). The Indices (Table 3) show a good adjustment of this model, evaluated independently as well as analyzed toward nesting with the metric invariance model. The difference between the two comparative indices of Bentler is zero; the general adjustment index is .985 and the root mean square error of approximation is .025. Accepted then the strong invariance, the two evaluated models are equivalent toward the factorial coefficients and the intercepts.

The promotion of the culture factor reaches values of internal consistency above .85 in both samples (men and women); demonstrating adequate internal consistency; while the Cultural Identity factor reaches values below .70 showing a low internal consistency (Table 4).

\section{Contrasts of the means of the factors among women and men}

Once proved the factorial invariance, the differences among the means of the factors from the two groups were estimated taking as a reference the men's sample, establishing 0 as the value of the means for this sample, considering freely the value of the means for the sample of women. Restrictions about regression coefficients and intercepts required for the contrast among the means made automatically through the software AMOS 21 (Arbuckle, 2012). The results of the comparisons between means indicated that the mean of the factors Promotion of the culture and Cultural Identity were significantly higher (0.520, p $<0.001$ y $0.340, p<0.001$ respectively) in women.

Table 3 Goodness of fit indexes of each of the models tested in the factorial invariance.

\begin{tabular}{lllccccc}
\hline Model & \multicolumn{2}{l}{ Fit Indexes } & & & & \\
\cline { 2 - 7 } & $\chi^{2}$ & gl & GFI & NFI & CFI & RMSEA & AIC \\
\hline Model without restrictions & $80.370^{*}$ & 44 & .988 & .987 & .994 & .023 & 172.370 \\
Metric Invariance & $99.379 *$ & 52 & .986 & .984 & .992 & .024 & 175.349 \\
Strong factor invariance & $106.500^{*}$ & 55 & .985 & .983 & .992 & .025 & 176.500 \\
\hline
\end{tabular}

Note: ${ }^{*} \mathrm{p}<.05$; GFI $=$ goodness of fit index; NFI = normed fit index; CFI = comparative fit index; RMSEA = root mean square error of approximation; AIC = Akaike information criterion

Table 4 Coefficient omega and alpha for the factors obtained

\begin{tabular}{lllcl}
\hline & \multicolumn{3}{c}{ Women } & \multicolumn{3}{c}{ Men } \\
\cline { 2 - 5 } Factor & $\Omega$ & $\alpha$ & $\Omega$ & $\alpha$ \\
\hline 1. Promotion of the culture & .869 & .880 & .872 & .884 \\
2. Cultural Identity & .602 & .616 & .600 & .640 \\
\hline
\end{tabular}




\section{Conclusion}

From the results, analysis and discussion shown and taking in consideration that the main objective of this study was to examine the factorial structure and the measure of the invariance of this structure in university students, we can conclude the following:

1) The Confirmatory Factorial Analysis, in both samples, indicated that the adjustment of the data to the theoretical model of 9 items grouped in two factors is optimal. At the same time that the two factors obtained, in general, adequate standardized factorial saturations. Also, the factors correlate among themselves in a positive way and statistically significant, which shows that, as Self-Efficacy perceived increases in some of the factors, the other one increased as well.

2) The factor promotion of the culture showed adequate internal consistency, while the internal consistency of Cultural Identity factor was below the acceptable; this probably due to the small number of items of the factor.

3) Along with all the above, the results of the analysis of the factorial invariance between samples; indicate a high congruence between pairs of factors. Suggesting the existence of strong evidence of cross-validation of the measure and therefore the stability of the structure, until the contrary is proved.

4) The comparisons between the groups reflect significant differences in favor to women, in the means of the factor promotion of the culture and Cultural Identity. Suggesting that women perceive themselves a little more self-efficient than men in relation to those factors.

In summary, the analysis of the psychometric properties has shown that a two-factor structure is viable and appropriate in accordance with established psychometric requirements when informants are the students themselves. The structure of two factors, based on statistical and substantive criteria, has shown adequate indicators of adjustment, reliability and validity. However, we believe that further studies are necessary in order to corroborate or refute the data obtained in this investigation.

\section{References:}

Abalo, J., Lévy, J., Rial, A., \& Varela, J. (2006). Invarianza factorial con muestras múltiples. In J. Lévy (Ed.), Modelización con Estructuras de Covarianzas en Ciencias Sociales (pp. 259-278). Madrid: Netbiblo.

Adeyemo, D. A. (2007). Moderating Influence of Emotional Intelligence on the Link Between Academic Self-efficacy and Achievement of University Students. Psychology Developing Societies, 19(2), 199-213.

Arbuckle, J. R. (2012). AMOS users guide version 21.0. Chicago, IL: Marketing Department, SPSS Incorporated. 
Blanco, H., Martínez, M., Zueck, M. d. C., \& Gastélum, G. (2011). Análisis psicométrico de la escala autoeficacia en conductas académicas en universitarios de primer ingreso. Actualidades Investigativas en Educación, 11(3), 1-27.

Blanco, H., Ornelas, M., Tristán, J. L., Cocca, A., Mayorga-Vega, D., LópezWalle, J., \& Viciana, J. (2013). Editor for creating and applying computerise surveys. Procedia Social and Behavioral Sciences, 106, 935-940. doi:http://dx.doi.org/10.1016/j.sbspro.2013.12.105

Brown, S. D., Tramayne, S., Hoxha, D., Telander, K., \& Lent, R. W. (2008). Social cognitive predictors of college students' academic performance and persistence: a meta-analytic path analysis. Journal of Vocational Behavior, 72(3), 298-308.

Caprara, G. V., Fida, R., Vecchione, M., Del Bove, G., Vecchio, G. M., \& Barbaranelli, C. (2008). Longitudinal analysis of the role of perceived efficacy for self-regulated learning in academic continuance and achievement. Journal of Educational Psychology, 100(3), 525-534.

Cartagena, M. (2008). Relación entre la autoeficacia y el rendimiento escolar y los hábitos de estudio en alumnos de secundaria. Revista Iberoamericana sobre Calidad, Eficacia y Cambio en Educación, 6(3), 59-99.

Chávez, A., Peinado, J. E., Aguirre, J. F., Ceballos, O., \& Rivero, J. G. (2014). A gender study of self-efficacy perceived in Socio-cultural environment in Mexican university students in the health area. Science Journal of Education, 2(3), 85-88. doi:10.11648/j.sjedu.20140203.13

Cheung, G. W., \& Rensvold, R. B. (2002). Evaluating goodness-of-fit indexes for testing measurement invariance. Structural Equation Modeling, 9(2), 233-255. doi:10.1207/s15328007SEM0902_5

Gelabert, E., García-Esteve, L., Martín-Santos, R., Gutiérrez, F., Torres, A., \& Subirà, S. (2011). Psychometric properties of the Spanish version of the Frost Multidimensional Perfectionism Scale in women. Psicothema, 23(1), 133-139.

Montero, I., \& León, O. (2005). Sistema de clasificación del método en los informes de investigación en Psicología. International Journal of Clinical and Health Psychology, 5, 115-127.

Muñoz, F., Zueck, M. C., Gastélum, G., \& Guedea, J. C. (2012). Composición factorial de una escala de autoeficacia en el ámbito sociocultural en universitarios de ingeniería. Formación Universitaria, 5(5), 39-50.

Ornelas, M., Blanco, H., Gastélum, G., \& Chávez, A. (2012). Autoeficacia Percibida en la conducta Académica de Estudiantes Universitarias. Formación Universitaria, 5(2), 17-26. doi:10.4067/S071850062012000200003 
Pajares, F. (2001). Self-efficacy beliefs in academic settings. Review of Educational Research, 66(4), 543-578.

Peinado, J. E., Viciana, J., Blanco, J. R., \& Blanco, H. (2014). Perceived self-efficacy in the sociocultural sphere with mexican university students. Differences between men and women. European Scientific Journal, 10(8), 59-68.

Revelle, W., \& Zinbarg, R. E. (2009). Coefficients alpha, beta, omega and the glb: comments on Sijtsma. Psychometrika, 74(1), 145-154. doi:10.1007/s11336-008-9102-z

Salanova, M., Llorens, S., \& Shaufeli, W. B. (2011). "Yes, I can, I feel good, and I just do it!” On gain cycles and spirals of efficacy beliefs, affect, and engagement. Applied Psychology: An International Review, 60(2), 255-285. Sansinenea, E., Gil, L., Agirrezabal, A., Larrañaga, M., Ortiz, G., Valencia, J. F., \& Fuster, M. J. (2008). Autoconcordancia y autoeficacia en los objetivos personales: ¿Cuál es su aportación al bienestar? Anales de Psicología, 24(1), 121-128.

Saunders, J., Davis, L., Williams, T., \& Williams, J. H. (2004). Gender differences in self perceptions and academic outcomes: A study of AfricanAmerican high school students. Journal of Youth and Adolescence, 33(1), 81-90.

Schmidt, V., Messoulam, N., \& Molina, F. (2008). Autoconcepto académico en adolescentes de escuelas medias: presentación de un instrumento para su evaluación. Revista Iberoamericana de Diagnóstico y Evaluación Psicológica, 1(25), 81-106.

Thompson, B. (2004). Exploratory and Confirmatory Factor Analysis. Understanding concepts and applications. . Washington, D C: American Psychological Association. 